\title{
UN RARO CASO DE HIALOHIFOMICOSIS EN UÑAS POR POLYPAECILUM INSOLITUM. G.SMITH
}

\author{
E. Piontelli L - M.A. Toro S.M. \\ Universidad de Valparaiso Facultad de Medicina \\ Cátedra de Micología. - Casilla 92 V Valparaíso \\ J. Testar \\ Hospital Van Buren. Servicio de Dermatologá. \\ Valparafso.
}

Palabras clave: Onicomicosis, Polypaecilum insolitum, Hialohifomicosis.

Key words: Onychomycosis, Polypaecilum insolitum Hyalohyphomycosis.

RESUMEN

Se presenta un caso clínico de un varón de 63 arios con una rara infección en las urias de los pies por Polypaecilum insolitum Smith, agente etiológico fúngico oportunista no descrito con anterioridad en el país y raro en la literatura. La anamnesis del paciente incluye antecedentes antiguos de alcoholismo crónico, cirrosis hepática compensada, neumopattas repetidas y antecedentes de TBC pulmonar. Además presenta lesiones dermíticas crónicas de ambas extremidades inferiores, con úlceras infectadas a repetición de evolución superior a los 30 años. Se aportan datos micro y macromorfológicos para su diagnóstico diferencial.

\section{INTRODUCCION}

- El género Polypaecilum, fue descrito por G. Smith (1961), para incluir algunas cepas erroneamente clasificadas como Scopulariopsis, una de ellas recibida en el CMI en Diciembre de 1958, aislada del conducto auditivo externo de un paciente. Esta cepa era idéntica a la descrita anteriormente por Coutelen y col. (1955), como Scopulariopsis insolita, aislada de un tumor micótico pulmonar, pero sin diagnosis latina.

\section{SUMMARY}

[ $A$ rare case of Hyalohyphomycosis in nails by Polypaecilum insolitum Smith ]

A clinical case of a 63 years old male with a rare infection on the nails by Polypaecilum insolitum Smith is informed. It is an opportunistic etiologic agent not previously described in the country and rare in the mycological literature. The patient's anamnesis included earty precedent of chronic alcoholism, balanced hepatic cimhosis, iterative pneumopathies and lung TBC. Moreover, he presented chronic dermitic lesions on booth legs with iterative infected ulcer of supperior evolution up to the age of 30 years. Micro and macromorphological date is included for its differential diagnosis.
Yamashita (1956), describe dos peculiares hongos bajo el nombre provisional de Scopulartopsis divaricata sp. nov. y S. divaricata var. alba. Hikita (1957), adoptó la misma denominación para describir algunos aislamientos idénticos. Ambos autores reconocen que las estructuras conidiogénicas observadas no eran típicas del genero Scopulariopsis, pero no establecen un nuevo género.

Yamashita y Yamashita (1972), al reexaminar estos aislamientos y al compararlos con 36 cepas aisladas en casos de otomicosis y con la cepa descrita por G. Smith (1961), reconocen la similitud con Polypaecilum insolitum. 
En Chile, el género no ha sido reportado en la literatura micológica, y este es el primer hallazgo clínico, a pesar que posteriormente lo hemos detectado 2 veces en harinas de pescado analizadas para la busqueda de especies toxicogénicas. Sus habitat descritos son: en literas vegetales, suelo, viruta de madera y nidos de pájaros. En el género existen 3 especies: P. capsici (van Beyma) G. Smith, P. botryoldes (Brooks \& Hasford) Rao \& de Hoog, y la especie tipo P. insolitum G. Smith. Thermoascus thermophilus von Arx ( = Dactylomyces thermophilus Soop), posee también un anamorfo sin nominación incluido en Polypaecilum.

G. Smith (1961), M.B. Ellis (1971) y con ciertas dudas Yamashita y Yamashita (1972), consideran a P. insolitum un hongo de conidiogénesis anelídica, como así Charmichael y col. (1980), lo incluyen en su clave con las siguientes alternativas: amero, de cadenas basípetas, hialo, anelídico (?). Ellis (1971) lo considera dematiáceo, a pesar que por sus características de cultivo presenta micelio hialino.

Su ontogenia conidial es semejante a Scopulariopsis, sin embargo la presencia de varios locus conidiógenos en el ápice de un conidióforo simple o ramificado ha llevado al parecer a conclusiones erróneas en el pasado (considerarlo anelídico).

Hughes (1951), propone por primera vez el término de polifiálide para las células conidiógenas de Lasiosphaeria hirsuta (Fries) Ces. \& deNot., por la presencia de más de un locus conidiógeno, desde los cuales nace una sucesión basípeta de fialoconidios. Esta terminología se ha aplicado con posterioridad en las descripciones de otros géneros (Codinea, Phialophora, etc.), o en variaciones de la conidiogénesis fiálidica normal. Malloch y Cain (1972), describen el anamorfo de Dactylomyces thermophilus, como semejante a Polypaecilum, el cual posee conidioforos ramificados dicotómicamente que terminan en pares múltiples de fiálides (no emplean el término de anélides).

Cole y Samson (1979), enmiendan el origen anélidico del conidio en $\mathbf{P}$. insolitum, por el de fiálidico, acorde a sus observaciones por microscopía electrónica, por la producción de varias y simultáneas fiálides funcionales sobre una célula fértil (polifiálide). Comentan además, que el concepto de fiálide debe ser corregido de la siguiente manera: "La fíalide puede tener 2 o más locus conidógenos activos y concurrentes (Ej. P. insolitum). Es difícil establecer si estos locus conidiógenos son sincrónicos, condición que parece observarse a la microscopía óptica.

\section{MACRO Y MICROMORFOLOGIA}

Aspecto de las colonias: A $27^{\circ} \mathrm{C}$, su diámetro en Papa dextrosa agar es de 6-7 mm, a los 6 días de incubación, y de $11-12 \mathrm{~mm}$ a los 10 días. Mientras a $37^{\circ} \mathrm{C}$ es de 9 y $14 \mathrm{~mm}$ respectivamente. A $27^{\circ} \mathrm{C}$ las colonias presentan un color gris verdoso más intenso en los márgenes, planas en los bordes pero solevantadas a surcadas en el centro. Reverso verde oliváceo oscuro, que se torna café con el tiempo. Abundante pigmento amarillo claro que difunde a todo el agar. A $37^{\circ} \mathrm{C}$ las colonias son más blanquecinas, aterciopeladas, con tonalidades verde grisáceas dispersas, con el mismo color en el reverso. El pigmento difusible a pesar de ser siempre de color amarillo, tiende con el tiempo a tornarse más café. En Agar Sabouraud, las colonias no diferen mayormente de lo descrito para Papa dextrosa, salvo un aumento en el diámetro a ambas temperaturas.

\section{MICROSCOPIA OPTICA}

Micelio hialino poco septado donde se aprecian conidióforos hialinos, aseptados o raramente septados,de diferentes tamaños, 2-4,2 x 6,6-47 um, pocas veces simple, mayoritariamente ramificado en el ápice o lateralmente a diferentes alturas, de aspecto liso. No mantiene un grosor uniforme en su crecimiento y puede parecer deformado o nodoso hacia el ápice. La falta de septos constantes no permite diferenciar la mayoría de las veces una célula conidiógena y el conidióforo en conjunto debe interpretarse como tal, el que presenta en su ápice (o lateralmente), proyecciones cortas o largas de aspecto cilíndrico, bastante variable en tamaño de 1,2 - 2,3 de ancho por 2,8 - 9 (-13) um de largo. Estas proyecciones (polifiálides) que nacen mayoritariamente desde 2 locus conidiógenos apicales divergentes, le otorgan la forma característica de las antenas de un caracol, sin embargo no existe un claro orden de aparición y los locus apicales o laterales, pueden disponerse en forma de cortas ramas (Fig. D), o incluso con tendencia simpodial (Fig. E). En la base de estas prolongaciones que debemos interpretar individualmente como fílides, puede apreciarse a veces un engrosamiento de la pared que a la microscopía optica aparece como una condensación del material de pared de color más denso que el resto (Fig. E, zona blanca refringente indicada por la flecha). Esta situación puede interpretarse como una fiálide naciente del nuevo locus conidiógeno a expensa de la pared interna (enteroblástica), por su aspecto más hialino y su delgada pared.

Los conidios nacen basipetamente, en cadenas desordenadas, divergentes, no ramificadas; son de forma ovoide, subglobosos a globosos, variando en 
tamaño en los extremos de las cadenas por los diferentes tiempos de maduración. Los más viejos de forma globosa, tienen un tamaño que oscila entre $\operatorname{los} 4,7$ y 7,2 um de diámetro. Al madurar su pared se torna de aspecto doble, gruesa, ondulada o rugosa (Fot. F), con un color grisáceo a café. La presencia de clamidosporas es común en los cultivos viejos, pudiendo presentarse en forma terminal o intercalar, de aspecto elíptico, subglobosas o globosas, cuyo eje largo no sobrepasa en nuestra cepa los 10 um de largo.

\section{CASO CLINICO}

Paciente de sexo masculino, 63 años de edad, con antecedentes de poliomelitis en la infancia y distrofias en extremidades inferiores, con parálisis parcial que presenta desde unos 40 años, lesiones crónicas de prúrigo y dermitis en extremidades inferiores, eccematosas, que se ulceran periódicamente y se infectan en forma secundaria. Antecedentes de bebedor de vino en forma exagerada por muchos años, con fibrosis hepática moderada compensada y TBC pulmonar tratada inactiva.

Desde 1980, se estudia etiología de eccema de las piernas, descartando causas infeccionas (TBC cutánea, eritrasma, micosis). Se logra cicatrización de las úlceras, pero recidivan periódicamente por complicaciones infecciosas causadas por distintos gérmenes. En 1985 el estudio histológico solo revela dermitis crónica inespecífica. Nuevamente en el mismo año un nuevo estudio histológico revela: Lesión cutánea psoriasiforme y en 1988; dermitis subaguda de contacto tipo alérgico.

Se efectúa estudio micobacteriológico de la lesión, el cual revela en piel Estafilococos coagulasa $(-)$ y negativo a hongos.

Las uñas de los pies del paciente (Foto $\mathrm{A}$ ), se presentan engrosadas oscuras, fuertemente teñidas de color amarillo café en tonos opacos. En el cultivo bacteriológico se detecta abundante desarrollo de Estafilococos coagulasa (-), y al micoIógico micelio fino en ovillos (Foto B), con conidios finamente rugosos, redondos y con una pequeña base trunca. Se informa abundante desarrollo de Scopulariopsis sp. (cepa en estudio).

Dos semanas después del primer informe micológico se avisa al clínico que la cepa aislada provisionalmente bajo el nombre de Scopulariopsis se ha reclasificado como Polypaecilum insolitum G. Smith. Después de unos 4 meses se inicia el tratamiento de las lesiones ungueales con Ketoconazol vía general ( $400 \mathrm{mg} /$ día) por 20 días, al final de éstos, se remueven quirúrgicamente las uñas clínicamente afectadas, para continuar con una dosis menor del fármaco $(200 \mathrm{mg} /$ día $)$ por 3 meses consecutivos, además de la aplicación tópica del mismo. El paciente no presentó problemas hepáticos durante el tratamiento.

Se logra crecimento lento de las uñas nuevas en buenas condiciones clínicas. El cultivo micológico efectuado en Enero 1989 al final de casi 4 meses de tratamiento revela: Directo negativo a hongos. Cultivo: escaso desarrollo de Polypaecilum insolitum.

\section{DISCUSION Y COMENTARIOS}

Este nuevo caso de micosis oportunista, puede comentarse no solo por el hallazgo de su agente causal, sino por la compleja historia y cuadro clínico del paciente. En nuestra rutina de informes micologicos, las micosis oportunistas de las uñas ocupan cifras cercanas al $1 \%$ de los casos estudiados, donde los agentes más comunes involucrados integran los géneros Aspergillus, Fusarium y Scopulariopsis. En especial este último, suele aislarse la mayoría de las veces como contaminante en las muestras obtenidas por raspado ungueal (uña de los pies) junto a un agente primario, representado generalmente por un dermatofito.

Nuestro primer informe micológico fue de abundante presencia de Scopulariopsis sp. en todos los cultivos $\left(27\right.$ y $\left.37^{\circ} \mathrm{C}\right)$. En especial a $37^{\circ} \mathrm{C}$, los aislamientos estaban completamente libres de otros microorganismos. Nos llamó la atención el color, el pigmento difusible y el reducido tamaño de las colonias a los 10 días de incubación, como así el positivo examen directo en $\mathrm{KOH}$ al $20 \%$, donde observamos abundante micelio fino en ovillos con conidios redondos, finamente rugosos, agrupados a veces en cortas cadenas y con una pequeña base trunca no siempre visible. Esta característica es común de ciertos aislamientos que normalmente corresponden al género Scopulariopsis (Piontelli y Toro 1988). Como nuestro primer informe fue provisional, una segunda muestra de raspado más profundo de la lámina ungueal del ortejo mayor del pie derecho, fue analizada a los 15 días arrojando los mismos resultados al directo y cultivo. En este segundo examen estudiamos con más detención el agente fúngico, empleando diferentes técnicas de tinción (Lactofenol con azul de algodón y Eritrocina al $10 \%$ de Amonio), así como microscopía de contraste de fase con preparados de 7 a 10 días de incubación, a 27 y $37^{\circ} \mathrm{C}$., lo cual permitió la correcta identificación de la especie involucrada.

Un tercer muestreo debía realizarse 30 días después, pero el paciente no se presentó y solamente pudimos contactarlo a los 3 meses, obteniéndose nuevamente los mismos resultados de 

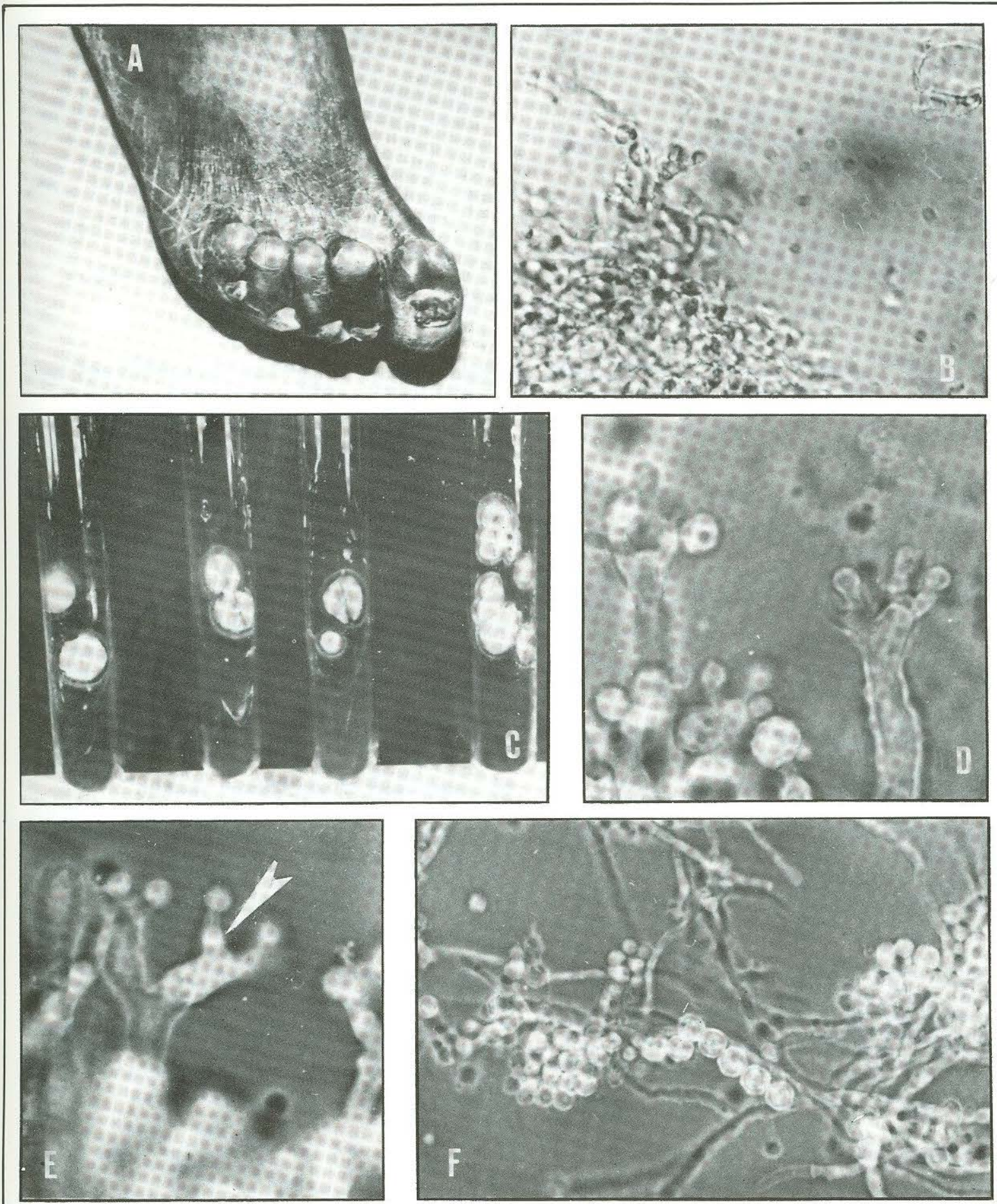

A. Aspecto clínico de las uñas de los pies. B. Hifas ramificadas y conidios agrupados al examen directo en $\mathrm{KOH}(400 \mathrm{x})$. C. Primer cultivo original de Polypaecilum insolitum en Agar Sabouraud con CAF a los 12 días de incubación. D. Conidióforo con polifiálides y conidios $(1200 \mathrm{x})$. E. Aspecto simpodial de las polifiálides y concentración de elementos de pared en su base (indicados por una flecha) (1200 x). F. Conidios rugosos agrupados en masas y cortas cadenas en cultivo $(700 \mathrm{x})$. 